\title{
Does virtue ethics allow us to make better judgments of the actions of others?
}

\author{
Liezl van Zyl, University of Waikato
}

Virtue ethics has now well and truly established itself as one of the main normative theories. It is now quite common, and indeed, expected, for virtue ethics to be included, alongside deontology and consequentialism, in any Moral Philosophy syllabus worth its salt. Students are typically introduced to virtue ethics only after studying the other two normative theories, and this often sets the scene for various sorts of misunderstandings, with students expecting virtue ethics to be based on the same set of rules and assumptions as its rivals. Or at least, that is my experience. In this paper I want to focus on one such misunderstanding, which arises when trying to apply virtue ethics to our judgments of other people's actions and behaviour. Although there are countless ways in which a theory can be misunderstood, it is worth guarding against this one in particular, given that it can lead someone who takes virtue ethics seriously to act in ways that are not virtuous, or even vicious.

I begin by making a few remarks about the role of normative theory, and then go on to give four examples of how applying virtue ethics can lead to poor behaviour. In the final section I identify the mistake in question and conclude by noting how it can be avoided.

\section{Normative theory}

Moral philosophers generally agree that normative theory, specifically, its account of right action, has two important functions: It is supposed to provide action guidance, that is, it should help me answer the question, "What ought I do?", and it should allow me to assess or evaluate actions as either right or wrong, good or bad, justified or unjustified. As William Frankena writes:

The ultimate concern of the normative theory of obligation is to guide us in the making of decisions and judgements about actions in particular situations. A main concern, of course, is to guide us in our capacity as agents trying to decide what we should do in this case and in that. But we want to know more than just what we should do in situations before us. We also wish to make judgments about what others should do, especially if they ask us about what we or they should have done, about whether what we or someone else did was right or wrong, and so on. We are not just agents in morality; we are also spectators, advisers, instructors, judges, and critics (Frankena 1973: 12).

In this passage Frankena identifies four tasks uses or functions of a normative theory, namely: 
1. first person action guidance ("to guide us in our capacity as agents trying to decide what we should do in this case and in that");

2. second person action guidance ("to make judgments about what others should do");

3. self-directed judgements ("to make judgments about... whether what we... did was right or wrong"); and

4. other-directed judgments ("to make judgments about ... whether what ... someone else did was right or wrong").

The question of whether virtue ethics provides adequate action guidance (1. and 2.) has been the subject of much debate among both normative theorists and applied ethicists (See, e.g. Annas 2004, 2015; Hursthouse 1991, 1999, 2006a, 2007; Gardiner 2003; Walker and Ivanhoe 2007). Although I will begin (and end) by making a few comments about acion guidance, my focus in this paper, is on other-directed moral judgments. Specifically, the question I want to consider is: Does virtue ethics allow us to make better judgments of the actions of others? I will use Hursthouse's qualified-agent account of right action, given that it is by far the most familiar one, but much of what I have to say will apply to other accounts as well.

\section{Hursthouse on right action}

Hursthouse gives the following criterion of right action:

An action is right iff it is what a virtuous agent would characteristically ... do in the circumstances (1999: 28).

Some critics complain that this is far too vague to provide adequate action guidance - if I am less than fully virtuous, how can I possibly figure out what a virtuous person would do my situation? Hursthouse responds by noting that the fully virtuous person would do what is courageous, just, honest, etc. and would not do what is cowardly, unjust, dishonest, etc. In effect, then, virtue ethics offers a long list of action-guiding rules, which she refers to as the "v-rules":

Not only does each virtue generate a prescription - do what is honest, charitable, generous - but each vice a prohibition - do not do what is dishonest, uncharitable, mean (1999: 36).

In a more recent paper, Hursthouse claims that the v-rules provide better action guidance than the sorts of rules that deontologists and utilitarians come up with, given that "there are so many more and they are so much more specific and subtly nuanced" (2006b: 107). Another advantage is that it also focuses our attention on the attitudes and emotions that are appropriate in the circumstances. It is not just that I should be generous by giving of my time and resources to help others, I should also do so gladly, happy in the knowledge that I am able to make a difference to the happiness of others. Hursthouse emphasizes that it is a 
mistake to expect virtue ethics - or any normative theory - to provide a set of rules or "a decision procedure which any reasonably clever adolescent could apply" (1999: 18). Deciding what to do, or applying the v-rules, requires wisdom and experience.

\section{Other-directed moral judgments}

Applying Hursthouse's account of right action when judging other people's actions appears to be a fairly straight-forward matter: We should consider whether the agent did what a virtuous agent would do in the situation, more specifically, whether he or she acted in a way that can be described as kind, courageous, honest, and so forth. Hursthouse gives us an example of how one could apply her biconditional in her well-known paper, "Virtue theory and abortion" (1991). Her aim in this paper is to demonstrate that virtue ethics can make an important - and distinctive - contribution to philosophical discussions about the morality of abortion. She argues that the morality of abortion depends on the sort of character a woman manifests in her reasons for terminating her pregnancy. Instead of focusing on the rights of women or the status of the foetus, the central question, for virtue ethics, is:

How do [the familiar biological facts about pregnancy, childbirth, and parenthood] figure in the practical reasoning, actions and passions, thoughts and reactions, of the virtuous and the nonvirtuous? What is the mark of having the right attitude to these facts and what manifests having the wrong attitude to them? (1991: 237)

Many commentators cite Hursthouse's paper as an example of how virtue ethics can provide action guidance. For instance, Justin Oakley (2013: 211) notes that:

[Hursthouse's] introduction of virtue and vice terms into contemporary abortion debates seemed to better match the concerns and experiences of many women (and men) considering whether to terminate a pregnancy. For many women who take themselves to have an overriding right to terminate their pregnancies nevertheless wonder about the sorts of considerations raised by Hursthouse when they are thinking about the moral justifiability of having an abortion in their current circumstances.

\section{Insensitivity and intrusiveness}

Hursthouse's commentators do not specifically address the question of whether thinking in terms of virtue and vice allows us to make better judgments of other people's actions (in this case, the act of procuring an abortion). But it is interesting to note that that the strategy that Hursthouse employs in this paper is not the one commonly used by applied ethicists, which is to present a moral dilemma and then to pose the question, "What should the agent do in these circumstances?" Instead, she presents a number of different circumstances in 
which a woman has had an abortion, and then considers whether they acted virtuously or viciously in doing so:

Consider, for instance, a woman who has already had several children and fears that to have another will seriously affect her capacity to be a good mother to the ones she has - she does not show lack of appreciation of the intrinsic value of being a parent by opting for abortion.... Nor, necessarily, does a woman who has decided to lead a life centered around some other worthwhile activity or activities with which motherhood would compete (1991: 241-2).

In this passage Hursthouse is clearly involved in the business of judging others' actions, and so it seems reasonable for us to follow the same kind of approach when judging other people's actions. Consider the case where my good friend Mary, a happily married mother of two, confides in me that she recently had an abortion because, she says, she simply could not cope with another baby. How am I to judge her act of procuring an abortion?

If I applied a deontological account of right action I might reason as follows: Mary (and everyone else, for that matter) has a duty not to kill an innocent person. The fetus is (or is not) a person, and so procuring an abortion is (or is not) wrong. Applying a rights-based approach, in turn, might have me reason that Mary (and everyone else) has a right to bodily integrity, which includes (or does not include) a right to have an abortion, and so Mary's action was (or was not) permissible. The thing to note about these judgments is that they are entirely impersonal - I need not know anything about Mary (other than the fact that she had an abortion) in order to make a judgment. Virtue ethics, by contrast, takes the agent's inner states - reasons, feelings, attitudes, and motives - as morally relevant. It is generally thought to be one of the advantages of virtue ethics that it judges actions, not merely as right or wrong, but in terms of "thicker" concepts, such as compassionate, generous, brave, selfish, cruel, and so on. These concepts are both evaluative and descriptive, and allow us to make judgments that are more nuanced and personal.

However, this very same feature of virtue ethics appears to be a disadvantage when it comes to applying the theory to our judgments of others. I encounter two closely related problems when trying to judge Mary's actions. The first is that an epistemic problem: I don't know why Mary thinks she cannot cope with another baby. It could be that she would have to cut down on luxuries, or spend less time socialising, in which case her actions are selfish, shallow, and grossly materialistic, as Hursthouse (1991: 241) puts it. Alternatively, she might have a very good reason, involving financial problems, mental illness, or the like, in which case the decision to have an abortion could well be the mature or responsible thing to do. As to Mary's attitude, her rather nonchalant demeanour might well be a sign that she's not taking the matter seriously at all, or it could be a mask she is wearing to enable her to cope with her decision. In short, if a virtuous action is one that involves acting for the right reasons, with the right emotions and attitudes, then I will very seldom have the information I need in order to make an accurate judgement. 
At this point one might argue that our frequent lack of knowledge of people's true motives and attitudes merely presents us with a practical problem, one that other normative theories encounter as well and that we should simply deal with as best we can. However, when we consider what is involved in dealing with the epistemic problem as best we can, a further difficulty emerges. Making an accurate judgment seems to require closer scrutiny of people, with the aim of revealing their true motives, feelings, and attitudes. What I should do, it seems, is to question Mary about her reasons for having an abortion. Why exactly does she feel she cannot cope with another baby? I might also look at her life style and general behaviour for clues as to whether she is shallow or grossly materialistic, and so on. However, I take it as obvious that this kind of scrutiny would be inappropriate - insensitive and intrusive. A good person who finds herself in my circumstances would not scrutinize and judge her friend but would offer comfort and support, and trust that she had a good reason for seeking an abortion. By applying virtue ethics when judging others, it appears, I run the risk of acting viciously myself.

\section{Meanness and uncharitability}

Applying virtue ethics to our judgments of others can also result in actions (or acts of judgment) that are mean and uncharitable. Consider the following example: A family is sitting around the table, having just finished their dinner, when the teenage boy thanks his mother politely and volunteers to do the dishes. The first thought that crosses her mind is, "What a lovely boy, always so kind and considerate." However, having just studied virtue ethics in an online Moral Philosophy course, she wonders whether her judgment is correct: "Did he truly do what a virtuous person would do in the circumstances? On the face of it, it would seem so. He offered to help, instead of complaining about the meal or rushing off to play video games, as so many teenagers do. But did he act from virtue? It could well be that he truly appreciates the efforts I made with dinner and that he really wants to make a contribution, and that the behaviour I am witnessing is a manifestation of true virtue (or at least virtue in progress). But it could also be that he is trying to manipulate me, and that he is acting selfishly and therefore wrongly. Then again, it could be that his behaviour is neither a manifestation of virtue nor of vice, but simply the result of a good upbringing: I have taught him to thank people and to be helpful, and that's what he is in the habit of doing." She decides to withhold her praise until she's discovered his true motives, and begins to watch her son more closely, looking for patterns of behaviour: Does he only offer to help when he expects to get something in return? Does he offer to help even when the task at hand is very unpleasant? Is he sincerely grateful or is he just in the habit of thanking people?, and so on.

Here, as in the abortion case, we encounter the problem of intrusiveness: Making an accurate judgment of her son's actions requires an inappropriate level of scrutiny of his behaviour over an extended period of time. But the case also demonstrates a further 
problem. By withholding praise and doubting whether her son's actions are truly kind and considerate, she herself is guilty of being mean and uncharitable. Unless he has given her good reason to suspect that he is selfish and manipulative, a good mother would respond to her son's offer by saying something like, "That's very kind of you," without subjecting this thought - and her son - to further critical scrutiny. More generally, she will be charitable in her judgments of others, giving them the benefit of the doubt, and not be too worried about whether she has sufficient evidence to support her judgements. This is not to say that it is never appropriate to scrutinize other people's behaviour in an attempt to figure out whether they and reliable and sincere. Rather, the point is simply that by being overly concerned with making correct judgments of other people's behaviour and character, we risk becoming mean and judgmental ourselves.

\section{Nit-picking and hypocrisy}

Another way in which we can act poorly when applying virtue ethics to our judgments of others is a result of the perfectionism inherent in many forms of virtue ethics. Virtues are ideals, or human excellences, and as such, we will hardly ever find instances of true virtue in action. Accordingly, if we judge others' actions in terms of virtue-and vice terms, our judgments will often be very harsh and hypocritical. Consider, for example, the recent case of David Pugh, a 55-year old man from West Midlands who fought off five machete-wielding intruders with his bare hands. According to news reports, the intruders stormed his house in the middle of the night, demanded cash and attacked Pugh's teenage son. Pugh used martial arts to fight them off. He and his son received various injuries, and his house was trashed, but the intruders eventually left empty-handed. ${ }^{1}$

Most people would describe Pugh's actions as truly brave or courageous, as indeed the news reports do. However, if we are serious about applying virtue ethics, it seems, we will have to rethink this claim. Is Pugh's actions an example of how a truly courageous person behaves? Here we might turn to Aristotle's discussion of "five kinds of courage improperly so called" in Book III.8 of The Nicomachean Ethics. For example, considering Pugh's training in martial arts and his claim that "instinct took over," we might wonder whether he displayed what Aristotle refers to as mere "optimism" or "sanguinity:" confidence in danger only because he has "conquered often and against many foes" and because he thinks he is "the strongest and can suffer nothing." Or we might suspect that he acted from anger or passion rather than choosing this course of action "because it is noble to do so, or because it is disgraceful not to do so." Finally, if Pugh had the option of appeasing the intruders by handing over cash or other valuables, then choosing to fight them off would have been extremely foolish.

\footnotetext{
${ }^{1}$ http://metro.co.uk/2018/02/14/dad-dog-hacked-fighting-off-machete-armed-robbers-break-7312973/
} 
Virtue ethicists (and virtue theorists, more generally) disagree about the nature of true courage, and so it is not uncommon - or inappropriate - for them to discuss the above kinds of question in the context of an academic debate. However, in the context of everyday life and when judging other people's behaviour, engaging is such discussions will often be inappropriate. Imagine, for example, that Pugh's friend, Gerhard, responds to others' comments about his bravery by saying something like: "Well, actually, his actions were not truly courageous because, as Aristotle says...." The problem here is not necessarily that Gerhard's judgment is incorrect. Rather, the problem is that he is being too harsh. Given that true courage, however it is defined, is rare, using it as a standard whereby to judge others will have the implication that our judgments will almost always be negative, and focused on how they fall short. A further, and related, problem is that Gerhard's judgment is almost certainly hypocritical, given that he would in all likelihood not have fared any better under the circumstances.

\section{Unfairness and harm}

Some of the risks discussed in the previous sections can be avoided (or mitigated to some extent) by noting a point that Hursthouse makes in a more recent paper (2006b). Here she argues that applying her biconditional does not necessarily require knowledge of other people's motives or inner states. In many contexts when we consider whether someone did what a virtuous person would do in the circumstances, it is appropriate to employ a thin notion of "what is done," one that does not include reference to the agent's inner states. She writes:

We have ... a strong interest in people doing what is honest, just, generous, charitable, or benevolent, etc.; to a large extent that's what keeps society ticking over and enables us to live together fairly pleasantly, and that - or those - purposes are served tolerably well even when a lot of people are doing what is right for the wrong reasons - out of fear of disapproval or the law, or because it suits them better than doing otherwise, or to curry favor or whatever (Hursthouse 2006b: 108-109).

In these contexts, we can evaluate an action as right (kind, generous, honest, etc.) without first having to discover the agent's true motives. We might claim that Kant's shopkeeper performed a right or honest action by giving a customer the correct change irrespective of his actual motives. However, Hursthouse goes on to argue that there are contexts in which it is appropriate to use a more demanding standard, one that includes a consideration of the agent's motives, feelings and attitudes. She writes:

Thinking of the virtuous agent as the one who sets the standard to which we should all aspire, we get a richer notion of "what is done." What you do does not count as right unless it is what the virtuous agent would do, say, "tell the truth, after much painful thought, for the right reasons, feeling deep regret, having put in place all that 
can be done to support the person on the receiving end afterwards." Only if you get all of that right are you entitled to the satisfactory review of your own conduct... [S]imply making the right decision and telling the truth is not good enough to merit approval (2006b: 109).

It is interesting to note that Hursthouse is talking about the evaluations we make of our own behaviour (self-directed judgments) in this passage. Although we can certainly be overcritical of our own behaviour, many of the problems - to do with intrusiveness, hypocrisy, and meanness - do not arise in this context. I know very well that I was motivated purely by malice when I told the truth about $C$, and so I cannot feel satisfied about my conduct - I can and should aim to do better. And if I am unsure about my true motives, then some introspection or self-scrutiny is entirely appropriate for it aids me in my attempt to become a better person. Interestingly, however, the example that Hursthouse uses to illustrate her claim that it is sometimes appropriate to use a more demanding standard, is of an other-directed judgment:

There I was, confident in assessing the plain-speaking of a colleague in a meeting as right, because honest - just the kind of straightforwardness we need in order to come to mutual decisions effectively and enable the department to run. And then I discover that the truth-teller is in fact usually evasive, manipulative, and plain mendacious in such meetings, and that his truth-telling on this occasion was motivated purely by spite, and I reassess it. "The ratbag!" I say. "What a rotten thing to do, to say that just to upset so and so." And if you press me on whether his action wasn't, all the same, right in some way, because honest, I shall say (a) that it would have been right, because honest, coming from, for example, John, but (b) that it wasn't honest coming from him and he would have done better to hold his tongue (2006b: 109).

Hursthouse concludes this passage by noting that "my biconditional works" - presumably, she means by this that it allows us to make accurate judgments. And so it seems reasonable to see it as an example of how we should apply virtue ethics when judging others. However, if we try to follow her lead in this regard, we soon run into trouble. To illustrate, imagine overhearing the following exchange:

Jack: When I first joined the department I thought Paula was very helpful, giving me just the kind of information I needed to settle in. But then I discovered that she's in fact selfish and manipulative, and was only being helpful because she needed my vote at the Board meeting. What a ratbag! Such a rotten thing to do, trying to help me just to use me!

Alice: But how do you know she's selfish and manipulative? What if she's really just trying to be helpful? 
Jack: Oh, I'm very sure. I talked to a couple of people who know her well, and they both say the same thing. She has quite the reputation around the faculty. And I've seen it with my own eyes: she's only ever helpful when there's something in it for her. So just watch out, you cannot trust her.

Jack is focused on making a judgment of Paula's actions, but in the course of doing so he is acting rather deplorably himself. Whereas Hursthouse stipulates that the plain-speaking colleague is "in fact usually evasive, manipulative, and plain mendacious in such meetings," Jack cannot be certain that Paula is in fact selfish and manipulative. He could well be mistaken, and the mistake in question is not merely theoretical. Rather, it is one that can have a significant impact on Paula and her relationships with co-workers. By making - and sharing - an inaccurate judgment of Paula he will be guilty of treating her unfairly and quite possibly harming her. But even if he is not mistaken, Alice might feel uneasy about the amount of time and effort Jack has devoted in pursuit of making an accurate judgment of Paula's actions and character. Shouldn't he focus more of his attention on improving his own actions and character and less on judging the behaviour of others?

\section{Good (virtuous) judgment}

These examples of vicious judgment point to a tension between Moral Philosophy and moral practice. As philosophers interested in questions about virtue and right action, we are concerned with making judgments that are accurate. We want to know, for example, what true courage or generosity consists in. We want to know when it is true to claim, for example, that having an abortion is self-indulgent, callous, and irresponsible. We get to judge the actions of hypothetical agents, and we are given all the relevant facts (or we just make them up as we go). We don't have to worry about being unfair, unkind, judgmental, or hypocritical.

However, as agents trying to live virtuously, we don't have the omniscience of the moral philosopher. We usually don't have the relevant facts - about other people's motives, attitudes and circumstances - that are needed for making accurate judgements. And the attempt to obtain this information will often require an inappropriate amount of scrutiny and interference in other people's lives. We are not, as Frankena (1973: 12) puts it, mere spectators, judges, or critics, sitting at a distance from those we judge. We are judging people with whom we stand in some kind of relationship, and our acts of judgement can affect them: they can be unkind, judgmental, hypocritical, or uncalled-for, even while being accurate. Whereas the philosopher is concerned with making accurate judgements, this cannot be our goal in everyday encounters with others. And so it appears that we should not use a virtue-ethical criterion of right action when judging others.

The discovery of this tension might lead one to conclude that virtue ethics is selfundermining. A normative theory is supposed to allow us to make better judgments of other 
people's actions, and yet by applying its criterion of right action we risk acting viciously ourselves. Something has clearly gone wrong, but what?

To see what has gone wrong in the application of virtue ethics we need to reconsider our assumptions about the role of normative theory. Consequentialists and deontologists share the assumption that the central task of normative theory is to answer the philosophical question, "What makes an action right?" The criterion of right action can then be applied to particular cases. As we've seen, Frankena claims that it has four more specific functions, which is to help me: (1) decide what I should do in my present situation, (2) advise others about what they should do in their situation, (3) make an accurate judgment of the rightness of my own actions, and (4) make an accurate judgment of the rightness of other people's actions (See Frankena 1973: 12). None of these functions have priority over the others. They are just the different things one can do with an account of right action, depending on whether one is occupying the role of agent, adviser, judge, or critic. In each case, the criterion allows us to distinguish, from an impersonal point of view, actions that are right from actions that are wrong. If the theory shows that action $\mathrm{X}$ is wrong in circumstances $\mathrm{C}$ (because it is contrary to duty, for example, or because it fails to maximise utility), then applying this assessment to everyday cases would render the judgement that (1) I ought not to do X in C; (2) Y ought not to do X in C, (3) I acted wrongly by doing X in C, and (4) $Y$ acted wrongly by doing $X$ in $C$. In this sense, there are no interesting differences between these four judgments.

However, if we expect virtue ethics to produce a criterion of right action that can then be applied, from an impersonal point of view, when making moral decisions and judging others we run into trouble. Figuring out what a virtuous person would do in my situation is a very different business from judging whether someone else succeeded in acting virtuously. Consider, for example, a situation where it is clear that a virtuous person would be kind to a vulnerable woman. When I am the one finding myself in this situation, figuring out how to act kindly requires reflection of a very personal nature: I have to be careful not to raise my voice, in the way that I so often do, and not to dismiss her concerns as trivial. I might have to check, before I get involved in her affairs, that I am not driven merely by curiosity but that I truly care about her, and so on. Assuming that there is time for this, reflecting on the personal - my motives, thoughts and feelings, and my flaws and weaknesses - is entirely appropriate when I am deciding how to act. (Of course, if I were a fully virtuous person such reflection would be unnecessary, but alas, I am not.) By contrast, when the task at hand is making an accurate judgement of someone else's actions, of whether he succeeded in acting virtuously, we encounter the problems discussed above, leading us to conclude that when judging others, we should not apply a virtue-ethical criterion of right action.

We can avoid the problem by noting that virtue ethics - at least in the eudaimonist tradition - does not begin with an abstract philosophical question, "What makes an action right?" Instead, it begins with a question that is both practical and deeply personal, namely: "How should I live?" (or "What kind of person should I become?"). Unlike the question of what 
makes an action right, the question of how one should live is one that concerns each one of us insofar as we have an interest in living well. As Aristotle notes: "[W]e are inquiring not in order to know what virtue is, but in order to become good" (NE 1103b27-8). Aristotle is not engaged in an abstract philosophical pursuit (such as discovering the necessary and sufficient conditions for a trait being a virtue, or for an action being right). Instead, he is concerned with the question, "How should I, Aristotle, live?" and he is writing for people who are grappling with the very same question. What motivates virtue ethics, then, is the need for guidance on how to live. As Julia Annas puts it, "the entry point for ethical reflection [is] thought about my life as a whole and where it is going" (1993: 33).

If we consider the function of a virtue-ethical account of right action against this background, we see that it is a mistake to assume that (1) deciding what I should do, (2) advising others about what they should do, (3) judging my actions, and (4) judging other people's actions, are just the different things I can do with such an account. Instead, the primary concern of virtue ethics - and hence its account of right action - is to guide the individual in his or her quest to live well. It is in the course of figuring out how to live virtuously that the individual encounters the more specific question, "How should I judge others?" To interpret this question as a call for a philosophical account of right action, one that can be applied in particular situations to render judgements that are correct or accurate, would be a mistake. Rather, the person who poses this question is seeking action guidance: she wants to know how to judge well or virtuously.

The key, then, is to notice that the virtuous person's primary concern when judging others is not to judge accurately but to judge virtuously. Of course, the virtuous judge will be concerned with the truth, with determining whether someone is deserving of praise or blame. Fairness is an important virtue when judging others. But it is not the only virtue that is relevant in this context. A virtuous judge will also be careful to respect others' privacy, and not to subject them to unnecessary or unwarranted scrutiny. She will avoid being judgmental, but will also avoid the vice of nonjudgmentalism. ${ }^{2}$ She will know when it is appropriate to be kind and charitable in her judgments. When someone behaves in a way that is consistent with virtue, she will tend to assume that they are well-motivated, and be quick to praise them for their kindness or their courage. And when a good person acts in ways that are consistent with vice, she will be compassionate and forgiving, and will tend to assume that they weren't poorly motivated but made a mistake, or acted out of character. At other times, however, when someone behaves in ways that are obviously or undeniably vicious, she will be honest and courageous in voicing her disapproval.

\footnotetext{
${ }^{2}$ Andrei Zavaliy (2016) argues, in this regard, that consistent nonjudgmentalism, that is, "a refusal to voice moral disapproval of the behaviour of wrongdoers" is not a virtue, because it involves treating morality as optional.
} 


\section{Conclusion}

The problem of vicious judgment can be avoided by noticing that for virtue ethics, the question of how I should judge others is just one of a host of more specific moral questions that the individual encounters in the course of answering the more general question, "How should I live?" In this sense, the individual is always an agent and never merely a spectator, judge, or critic. He sometimes (perhaps often) acts as judge or critic, and the challenge is to figure out how to do this well - virtuously - if at all. When judging others, he should remember that he is the one deciding and acting; it is his virtue that is at stake.

As noted earlier, Hursthouse argues that it is unreasonable, given the complexity of moral life, to expect a normative theory to provide a "decision procedure" that any clever adolescent could apply when deciding how to act. We can now make a similar point with regards to other-directed moral judgments, namely that it is unreasonable to expect a normative theory to provide a tool or procedure that any clever adolescent could apply when judging other people's actions. Judging well is a complex matter. It involves knowing how to apply virtue and vice terms to other people's actions, and it involves doing so virtuously - fairly, charitably, generously, and so on.

\section{References}

Annas J (1993) The morality of happiness. Oxford University Press, New York

Annas J (2004) Being virtuous and doing the right thing. Proceedings and Addresses of the American Philosophical Association 78:61-75

Annas, J (2015) Applying virtue to ethics (Society of Applied Philosophy annual lecture 2014). Journal of Applied Philosophy. doi:10.1111/japp.12103

Aristotle (2009) The Nicomachean Ethics. Translated by Ross D and revised by Brown L. Oxford World's Classics, Oxford

Frankena W (1973) Ethics, $2^{\text {nd }}$ edn. Prentice-Hall, New Jersey

Gardiner P (2003) A virtue ethics approach to moral dilemmas in medicine. J Med Ethics. doi:10.1136/jme.29.5.297

Hursthouse R (1991) Virtue theory and abortion. Philos Public Aff 20:223-246

Hursthouse R (1999) On virtue ethics. Oxford University Press, Oxford

Hursthouse R (2006a) Applying virtue ethics to our treatment of the other animals. In:

Welchman J (ed) The practice of virtue: classic and contemporary readings in virtue ethics. Hackett, Indianapolis, pp 136-155 
Hursthouse R (2006b) Are virtues the proper starting point for morality? In: Dreier J (ed) Contemporary debates in moral theory. Blackwell, Malden, pp 99-112

Hursthouse R (2007) Environmental virtue ethics. In: Walker RL, Ivanhoe PJ (eds) Working virtue: virtue ethics and contemporary moral problems. Clarendon Press, Oxford, pp 155-172 Oakley J (2013) Virtue ethics and bioethics. In: Russell D (ed) The Cambridge companion to virtue ethics. Cambridge University Press, Cambridge, pp 197-220

Walker RL, Ivanhoe PJ (eds) (2007) Working virtue: virtue ethics and contemporary moral problems. Clarendon Press, Oxford.

Zavaliy AG (2017) On The Virtue of Judging Others. Philosophical Investigations, 40: 396413. doi:10.1111/phin.12141. 